\title{
Reproduction and mode of delivery in women with vaginismus or localised provoked vestibulodynia: a Swedish register-based study
}

Louise Möller, Ann Josefsson, Marie Bladh, Caroline Lilliecreutz and Gunilla Sydsjö

\author{
Linköping University Post Print
}

Tweet

N.B.: When citing this work, cite the original article.

Original Publication:

Louise Möller, Ann Josefsson, Marie Bladh, Caroline Lilliecreutz and Gunilla Sydsjö, Reproduction and mode of delivery in women with vaginismus or localised provoked vestibulodynia: a Swedish register-based study, 2015, British Journal of Obstetrics and Gynecology, (122), 3, 329-334.

http://dx.doi.org/10.1111/1471-0528.12946

Copyright: Wiley: 12 months

http://eu.wiley.com/WileyCDA/

Postprint available at: Linköping University Electronic Press

http://urn.kb.se/resolve?urn=urn:nbn:se:liu:diva-115325 
Reproduction and mode of delivery in women with vaginismus or localised provoked vestibulodynia : a Swedish register-based study

\section{Möller L, Josefsson A, Bladh M, Lilliecreutz C, Sydsjö G}

Division of Obstetrics and Gynecology, Department of Clinical and Experimental Medicine, Faculty of Health Sciences, Linköping University,

Linköping, Sweden

\section{Corresponding author:}

Gunilla Sydsjö

Department of Obstetrics and Gynaecology, and Department of Clinical and Experimental Medicine,

Linköping University

SE - 58185 Linköping, Sweden

Tel: +46 10103 3167; fax: +4613148156

e-mail: gunilla.sydsjo@lio.se

Running title: Reproduction in women with vaginismus

Word Count: 2172 


\begin{abstract}
Objective. To compare sociodemographics, parity and mode of delivery between women diagnosed with vaginismus or localised provoked vestibulodynia (LPV) to women without a diagnosis before first pregnancy.

Design. Retrospective, population-based register study.
\end{abstract}

Setting. Sweden.

Sample. All women born in Sweden 1973-1983 who gave birth for the first time or remained nulliparous during the years 2001-2009.

Methods. Nationally linked registries were used to identify the study population. Women diagnosed with vaginismus or LPV were compared to all other women. Odds ratios for parity and mode of delivery were calculated using multinominal regression analysis and logistic regression.

Main outcome measures. Parity and mode of delivery.

Results. Women with vaginismus/LPV were more likely to be unmarried $(\mathrm{P}=0.001)$, unemployed $(\mathrm{P}=0.012)$, have a higher educational level $(\mathrm{P}<0.001)$, a lower body mass index $(\mathrm{P}<0.001)$ and use nicotine during pregnancy $(\mathrm{P}=0.008)$. They were less likely to give birth (adjusted odds ratio [OR] 0.61, 95\% confidence interval [95\% CI] $0.56-0.67)$. Women with vaginismus/LPV more often delivered by caesarean section $(\mathrm{P}<0.001)$ especially for maternal request (adjusted OR 3.48, 95\% CI 2.45 -4.39). In women having vaginal delivery, those with vaginismus/LPV were more likely to suffer a perineal laceration (adjusted OR $1.87,95 \%$ CI $1.56-2.25)$.

Conclusions. Women with vaginismus/LPV are less likely to give birth and those that do are more likely to deliver by caesarean section and have a caesarean section based upon maternal request. Those women delivering vaginally are more likely to suffer perineal laceration. These findings point to the importance of not only addressing sexual function in women with 
vaginismus/LPV but reproductive function as well.

Keywords. Caesarean section, localised provoked vestibulodynia, reproduction, vaginismus. 


\section{Introduction}

Dyspareunia, pain during vaginal intercourse, affects $8.6-13.0 \%$ of women of reproductive age (1). Localised provoked vestibulodynia (LPV) is one of the most common causes (2), often accompanied by vaginsmus $(3,4)$. These conditions are difficult to separate, so dyspareunia and vaginismus are collapsed into one diagnostic entity in the Diagnostic and Statistical Manual of Mental Disorders, Fifth Edition called genitopelvic pain/penetration disorder. Genitopelvic pain/ penetration disorder is defined as one or more of the following; persistent or recurrent difficulties with vaginal penetration, pain during vaginal intercourse, fear/anxiety about vulvovaginal pain during or in anticipation of vaginal penetration and/or marked tensing of the pelvic floor muscles during attempted vaginal penetration (5). The aetiology is unknown and probably multifactorial. LPV has been associated with vaginal infections (6), polymorphisms in genes regulating the inflammatory response (7-9), a decreased pain-threshold (10), pain conditions such as irritable bowel syndrome and fibromyalgia (11), contradictory results regarding the use of oral contraceptives $(12,13)$ as well as psychological and psychosexual factors $(14,15)$. Vaginismus is currently viewed as a variable reflexive contraction of the pelvic floor muscles associated with phobic avoidance and anticipation of pain (16). Little is known about the afflicted women's reproduction, pregnancy and delivery outcome. Because of severe pain and/or vaginal spasm, these women might be unable to engage in vaginal intercourse and so suffer from infertility $(17,18)$. A register-based study in an Israeli hospital during the years 1988-2007 found an increased risk for delivery by caesarean section, vacuum extraction and the need to induce labour in women with vaginismus (19). A questionnaire-based case-control study in USA found a tendency towards an increased risk of delivery by caesarean section $(\mathrm{P}=0.07)$ in women with vulvodynia (18). 
The objective of this study with a large prospectively collected cohort from Swedish medical health registries was to investigate if reproductive patterns, mode of delivery and sociodemographic characteristics differ between women diagnosed with vaginismus or LPV before first completed pregnancy compared with women without a diagnosis. By access to nationwide registers, the study population comprises all women born in Sweden 1973-83 giving birth for the first time, if at all, during the years 2001-09.

\section{Methods}

From a cohort of all females born in 1973 to 1983, alive and still living in Sweden at 13 years of age $(n=494692)$, we extracted women giving birth for the first time or not at all during the years $2001-09(n=454913)$. The women were divided into two groups, one with women having been diagnosed with vaginismus and/or LPV between 2001 and $2009(n=2554$, $0.6 \%)$, and the other with women without a diagnosis $(n=445632,99.4 \%)$. Women diagnosed with vaginismus and/or LPV for the first time after pregnancy as well as women diagnosed with endometriosis, lichen sclerosus, lichen planus or lichen simplex chronicus (n $=6727,1.5 \%$ ) were excluded to avoid confounding. The final study population therefore comprised 448186 women. Obstetric data, data on birth complications as well as sociodemographic data were collected. Body mass index (BMI) was divided into five categories $\left(\leq 18.49 ; 18.5-24.99 ; 25.0-29.99 ; 30.0-34.99 ; \geq 35 \mathrm{~kg} / \mathrm{m}^{2}\right)$. Employment was defined according to Statistics Sweden's definition as a yearly income $\geq 39700$ SEK in the year 2006. BMI and nicotine use during pregnancy was only available for women giving birth during the study period.

\section{Data collection}

In Sweden all residents have a unique personal identification number making it possible to 
link data from different registers.

The Swedish Medical Birth Register (MBR) contains information on 98-99\% of all pregnancies leading to parturition in Sweden since 1973 (20). Obstetric data, BMI and nicotine use during pregnancy were retrieved from this register.

The National Patient Register (NPR) has recorded public outpatient care since 2001 and public inpatient care since 1987 (21). The diagnoses are based on The International Classification of Diseases (ICD) (22). The ICD-10 has been used since 1997. ICD-10 codes used to identify diagnoses were: vaginismus, F52.5 and N94.2; LPV, N76.3; endometriosis, N80.0- N80.9 and N97.8D; lichen sclerosus, L90.0 and N90.4; lichen planus, L43.9; lichen simplex chronicus, L28.0; mode of delivery, O80-O84; and birth complications, O60-O75. The Total Population Register (TPR) includes information on births, deaths, citizenship and marital status as well as migration and country of birth for Swedish residents born abroad(23). The Causes of Death Register records information on all deceased persons registered in Sweden at the time of death since 1961 (24).

The Education Register records data on highest educational level (25). Educational level was defined as the highest level of education in 2006.

The Multi-Generation Register is part of the TPR that records kinship (26). By this we could identify the parents of our study population.

\section{Statistics}

Women with vaginismus/LPV were compared with controls (women without a diagnosis). Univariate statistical differences were calculated using Pearson chi-square test. We estimated the risk of different modes of delivery by multinominal regression using vaginsmus/LPV, sociodemographic characteristics as well as perineal lacerations as explanatory variables. The adjusted odds ratio (adj. OR) for childbirth was calculated by logistic regression using 
working status, educational level and marital status as predictors. These covariates were chosen because they differed significantly between cases and controls. The risk of complications and birth injuries during labour and childbirth was calculated by logistic regression. Vaginismus/LPV, mode of delivery, macrosomia (birthweight $>4000 \mathrm{~g}$ ) and sociodemographic factors were set as predictors. These covariates were chosen because they possibly could independently impact the risk. The data were analysed using IBM SPSS version 20.0 (IBM SPSS Inc., Armonk, NY, USA). A P-value $<0.05$ was considered significant.

\section{Results}

In total, $2554(0.6 \%)$ women had been diagnosed with vaginismus or LPV, of these 220 women had been diagnosed with both vaginismus and LPV. These women had lower BMI $(\mathrm{P}<0.001)$, higher educational level $(\mathrm{P}<0.001)$, were more often $24-29$ years at first childbirth $(\mathrm{P}=0.040)$, nicotine users $(\mathrm{P}=0.008)$, unmarried $(\mathrm{P}=0.001)$ and more often unemployed $(\mathrm{P}=0.012$; Table 1).

During the study period 225778 (50.4\%) of the women gave birth. Women with vaginismus/LPV were more often nulliparous (60.4 versus $49.6 \%$; $<<0.001$; Table 2 ). These findings remained after adjustments for educational level, working status and marital status (adj. OR 0.61, 95\% CI 0.56-0.67; results not shown).

Childbirth by caesarean section as well as instrumental delivery were more common in women with vaginismus/ LPV (Table 2). Odds ratios showed a significantly increased risk for all deliveries except vaginal delivery and emergency caesarean section (Table 3). After adjusting for sociodemographic characteristics (age, marital status, BMI, educational level, working status and nicotine use) and birth injuries (perineal lacerations) the risk increased and was significant for elective caesarean section (adj. OR 1.42, 95\% CI 1.10-1.84), caesarean 
section on maternal request (adj. OR 3.48, 95\% CI 2.45-4.94) and emergency caesarean section (adj. OR 1.38, 95\% CI 1.10-1.75). The risk for instrumental delivery decreased and was non-significant (adj. OR 1.16, 95\% CI 0.95-1.41; Table 3).

Women with vaginismus/LPV had an increased risk of perineal lacerations during vaginal delivery (adj. OR 1.87, 95\% CI 1.56-2.25). No differences were found for other childbirthrelated complications (preterm labour, failed induction of labour, abnormalities of forces of labour, long labour, obstructed labour due to maternal pelvic abnormality, other obstructed labour, intrapartum and postpartum haemorrhage, fetal distress, umbilical cord complications, other obstetric trauma, retained placenta or complications of anaesthesia). No difference was found in the use of pain-relieving methods (spinal, infiltrative and epidural anaesthesia; pethidine; paracervical and pudendal block) during labour and childbirth.

\section{Discussion}

\section{Main findings}

In this study we found that women with vaginismus/LPV are less likely to have children and those that do are at an increased risk of giving birth by caesarean section. This latter finding is in line with research by Goldsmith et al. (19) who also found vaginismus to be an independent risk factor for caesarean section. We found that women with vaginismus/LPV were more likely to undergo caesarean section based upon maternal request. In primiparous women requesting caesarean section the most common reason for requesting a caesarean section is fear of childbirth (27). Hence, the higher likelihood of nulliparity and the high rate of caesarean section for maternal request in women with vaginismus/LPV may indicate an increased fear of childbirth, possibly because of fear of pain and vulvovaginal trauma.

The risk of caesarean section was not limited to elective caesarean section. Emergency 
caesarean section was also more likely for women with vaginismus/LPV despite the finding that these women had lower BMIs and were younger at first childbirth, which should decrease the risk of emergency caesarean section. The indications for emergency caesarean section did not appear to differ between groups, but available data are limited. It is possible that the observed higher rate of emergency caesarean section reflects difficulties in performing vaginal examination (19), resulting in an unplanned caesarean section.

Vaginismus/LPV was found to be a risk factor for perineal lacerations even after adjusting for mode of delivery, macrosomia (birthweight $>4000 \mathrm{~g}$ ) and sociodemographic variables. This has not been observed before. As Rosenbaum and Padoa (28) hypothesised that this may be caused by difficulties in relaxing the pelvic floor to allow for stretching during the second stage of labour. The inflammation observed in LPV might also make the tissue more fragile. This finding is important because women with vulvodynia have been shown to experience genital pain after perineal lacerations and episiotomy for longer than other women (18). Hence, one could argue that these women may benefit from a caesarean section to avoid vulvovaginal trauma in light of the higher risk of perineal laceration during vaginal delivery that we observed and the possible longer-term pain arising from such trauma (18). Furthermore, if the delivery is perceived as a fearful experience it could exacerbate the sexual dysfunction by adding more negative associations.

In line with other studies (6) women with vaginismus/LPV were less likely to give birth compared with women without a diagnosis even after adjusting for sociodemographic variables. We were unable to obtain data as to whether women with vaginismus/LPV wished to give birth or if they had conceived but miscarried or undergone abortion. It is therefore impossible to draw any conclusions regarding fertility desires in these women. Our results may merely reflect that these women wish to give birth to a lesser extent than other women. However, they appear to indicate that vaginismus and LPV independently predict the 
likelihood of remaining nulliparous. Severe pain and/or vaginal spasm limit the ability to engage in vaginal intercourse, which naturally affects the possibility of becoming pregnant. A behavioural approach involving education, counselling and sensate focus techniques for affected couples as well as desensitisation of the vulva and vagina have been shown to be a successful in resolving vaginismus and achieving pregnancy. Emphasis was put on the importance of including the partner in treatment because male partners can develop secondary erectile dysfunction (17). Surgical interventions (29) as well as multidisciplinary methods using desensitisation, counselling and education have been shown to be successful treatments for LPV (30).

Overall we found a lower prevalence of vaginismus/LPV than observed in earlier studies (31, 32). Since our results are based on diagnoses and earlier studies are primarily based on questionnaires this suggests there are a number of undiagnosed or misdiagnosed cases. It is possible that these women do not seek medical attention because sexual dysfunction is often perceived as embarrassing and difficult to discuss. Women with vaginismus/LPV differed from controls in sociodemographic characteristics; they had a tendency to be more educated, unmarried, unemployed, use nicotine and have a lower BMI. Other than a lower BMI, these differences have not been observed before; however, this is the first large epidemiological study in this area $(6,12-14,18,33)$.

\section{Strengths and limitations}

This study was based on a nationwide sample enhancing the validity and generalisability of our findings. By excluding women who were diagnosed with vaginismus and LPV after first childbirth we avoided confounding by genital pain postpartum. We excluded women giving birth before 2001 because the data from outpatient care, where most women with vaginismus and LPV are treated and diagnosed, only became available from 2001 onwards. This limited our case numbers. In addition, we could not obtain any information regarding women's 
fertility desires or previous fertility treatments, which would have helped interpretation of the reasons for an apparent increased likelihood of nulliparity.

\section{Interpretation}

Women with vaginismus/LPV have an increased risk of giving birth by caesarean section, to develop perineal lacerations during vaginal delivery and are more often nulliparous. To increase knowledge on fertility and fear of childbirth in women with LPV and vaginismus further prospective epidemiological studies including data on fertility treatments, abortions and fear of childbirth are needed.

\section{Conclusion}

Women with vaginismus/LPV require special attention in both gynaecological and obstetric practice. These women are more likely to remain nulliparous. Those that do give birth have an increased risk of delivery by caesarean section as well as requesting an elective caesarean section. Those delivering vaginally are more likely to suffer perineal lacerations. Whether women with vaginismus/LPV would benefit from treatment for possible fear of childbirth and be offered planned caesarean section remains to be investigated. Our findings point to the importance of not only addressing sexual function in such women but reproductive function also. In addition to treating the underlying complaint, women with vaginismus/LPV may need information on alternative methods to conceive such as self-insemination.

\section{Disclosure of interest}

The authors have no conflicts of interest to disclose.

\section{Contribution to authorship}

LM had the original idea for the study. GS, MB, AJ, CL and LM planned the study. LM and MB analysed the data and LM drafted the paper. All authors contributed to the interpretation of the data, revisions and gave input at all stages of the study. All authors have approved the 
final version of the manuscript.

Details of ethics approval

This study was approved by the Human Research Ethics Committee, Faculty of Health

Sciences, Linköping University \#2011-246-31. 2008-08-10.

Funding

Financial support was received from Medical Research Council of Southeast Sweden.

\section{References}

1. Danielsson I, Sjöberg I, Stenlund H, Wikman M. Prevalence and incidence of prolonged and severe dyspareunia in women: results from a population study. Scand J Public Health 2003;31:113-18.

2. Fugl-Meyer KS, Bohm-Starke N, Petersen CD, Fugl-Meyer A, Parish S, Giraldi A. Standard operating procedures for female genital sexual pain. J Sex Med 2013;10:83-93.

3. Engman M, Lindehammar H, Wijma B. Surface electromyography diagnostics in women with partial vaginismus with or without vulvar vestibulitis and in asymptomatic women. $\mathrm{J}$ Psychosom Obstet Gynaecol 2004;25:281-94.

4. Ter Kuile MM, Van Lankveld JJ, Vlieland CV, Willekes C, Weijenborg PT. Vulvar vestibulitis syndrome: an important factor in the evaluation of lifelong vaginismus? J Psychosom Obstet Gynaecol 2005;26:245-9.

5. American Psychiatric Association. Diagnostic and Statistical Manual of Mental Disorders, 5th edn. Arlington, VA: American Psychiatric Association, 2013 [dsm.psychiatryonline.org]. Accessed 1 June 2013.

6. Smith EM, Ritchie JM, Galask R, Pugh EE, Jia J, Ricks-McGillan J. Case-control study of vulvar vestibulitis risk associated with genital infections. Infect Dis Obstet Gynecol 2002;10:193-202.

7. Lev-Sagie A, Prus D, Linhares IM, Lavy Y, Ledger WJ, Witkin SS. Polymorphism in a gene coding for the inflammasome component NALP3 and recurrent vulvovaginal candidiasis in women with vulvar vestibulitis syndrome. Am J Obstet Gynecol 2009;200:303.

8. Babula O, Danielsson I, Sjoberg I, Ledger WJ, Witkin SS. Altered distribution of mannosebinding lectin alleles at exon I codon 54 in women with vulvar vestibulitis syndrome. Am J Obstet Gynecol 2004;191:762-6. 
9. Gerber S, Bongiovanni AM, Ledger WJ, Witkin SS. Interleukin-1 $\beta$ gene polymorphism in women with vulvar vestibulitis syndrome. Eur J Obstet Gynecol Reprod Biol 2003;107:74-7.

10. Heddini U, Bohm-Starke N, Grönbladh A, Nyberg F, Nilsson KW, Johannesson U. GCH1polymorphism and pain sensitivity among women with provoked vestibulodynia. Mol Pain 2012;8:68.

11. Nguyen RHN, Veasley C, Smolenski D. Latent class analysis of comorbidity patterns among women with generalized and localized vulvodynia: preliminary findings. J Pain Res 2013;6:303-9.

12. Bouchard C, Brisson J, Fortier M, Morin C, Blanchette C. Use of oral contraceptive pills and vulvar vestibulitis: a case-control study. Am J Epidemiol 2002;156:254-61.

13. Reed BD, Harlow SD, Legocki LJ, Helmuth ME, Haefner HK, Gillespie BW, et al. Oral contraceptive use and risk of vulvodynia: a population-based longitudinal study. BJOG 2013;120:1678-84.

14. Ehrström S, Kornfeld D, Rylander E, Bohm-Starke N. Chronic stress in women with localized provoked vulvodynia. J Psychosom Obstet Gynaecol 2009;30:73-9.

15. Desrochers G, Bergeron S, Landry T, Jodoin M. Do psychosexual factors play a role in the etiology of provoked vestibulodynia? A critical review. J Sex Marital Ther 2008;34:198-226.

16. ter Kuile MM, van Lankveld JJ, de Groot E, Melles R, Neffs J, Zandbergen M. Cognitivebehavioral therapy for women with lifelong vaginismus: process and prognostic factors. Behav Res Ther 2007;45:359-73.

17. Jindal UN, Jindal S. Use by gynecologists of a modified sensate focus technique to treat vaginismus causing infertility. Fertil Steril 2010;94:2393-5.

18. Nguyen RHN, Stewart EG, Harlow BL. A population-based study of pregnancy and delivery characteristics among women with vulvodynia. Pain Ther 2012;1:2.

19. Goldsmith T, Levy A, Sheiner E. Vaginismus as an independent risk factor for cesarean delivery. J Matern Fetal Neonatal Med 2009;22:863-6.

20. National Board of Health and Welfare, Centre for Epidemiology. The Swedish medical birth register; a summary of content and quality. 2003

[www.socialstyrelsen.se/Lists/Artikelkatalog/Attachments/10655/ 2003-112-

3_20031123.pdf]. Accessed 24 September 2012.

21. Centre for Epidemiology, National Board of Health and Welfare. Kodningskvalitet i patientregistret - Ett nytt verktyg för att mäta kvalitet. Stockholm, Sweden: National Board of Health and Welfare, 2013 (Article no 2013-3-10)

[www.socialstyrelsen.se/Lists/Artikelkatalog/Attachments/19005/2013-3-10.pdf]. Accessed 11 July 2013

22. National Board of Health and Welfare, Centre for Epidemiology. The Swedish version of 10th revision of WHO's international classification of diseases. 2010 [www.socialstyrelsen.se/ publikationer2010/2010-11-13]. Accessed 27 September 2012.

23. Statistics Sweden. A new total population register system. More possibilities and better quality. (Serial no. 2002:2). Örebro, Sweden: Statistics Sweden, 2002. 
24. National Board of Health and Welfare, Centre for Epidemiology. Causes of death 2011. 2012 [www.socialstyrelsen.se/Lists/Artikelkatalog/Attachments/19001/2013-2-30.pdf]. Accessed 23 July 2013.

25. Statistics Sweden. Educational attainment of the population 2004.2005 [www.scb.se/statistik/UF/UF0506/2005A01/UF0506_2005A01_SM_UF37SM0501.pdf]. Accessed 22 July 2013.

26. Statistics Sweden. Multi-generation register 2010. A description of contents and quality. 2011 [www.scb.se/statistik/_publikationer/BE9999_2011A01_BR_BE96BR1102.pdf]. Accessed 22 July 2013.

27. Nieminen K, Stephansson O, Ryding EL. Women's fear of childbirth and preference for cesarean section-a cross-sectional study at various stages of pregnancy in Sweden. Acta Obstet Gynecol Scand 2009;88:807-13.

28. Rosenbaum TY, Padoa A. Managing pregnancy and delivery in women with sexual pain disorders. J Sex Med 2012;9:1726-35.

29. Tommola P, Unkila-Kallio L, Paavonen J. Long-term well-being after surgical or conservative treatment of severe vulvar vestibulitis. Acta Obstet Gynecol Scand 2012;91:1086-93.

30. Backman H, Widenbrant M, Bohm-Starke N, Dahlof LG. Combined physical and psychosexual therapy for provoked vestibulodynia-an evaluation of a multidisciplinary treatment model. J Sex Res 2008;45:378-85.

31. Munday P, Green J, Randall C, Fox D, Singh M, Ismailijee F, et al. Vulval vestibulitis: a common cause of dyspareunia? BJOG 2005;112:500-3.

32. Oberg K, Fugl-Meyer AR, Fugl-Meyer KS. On categorization and quantification of women's sexual dysfunctions: an epidemiological approach. Int J Impot Res 2004;16:261-9.

33. Christensen BS1, Grønbaek M, Osler M, Pedersen BV, Graugaard C, Frisch M. Sexual dysfunctions and difficulties in denmark: prevalence and associated sociodemographic factors. Arch Sex Behav 2011; 40:121-32. 
Table 1 Socio-demographic variables among women with vaginismus/LPV compared to controls (women without a diagnosis).

\begin{tabular}{|c|c|c|c|}
\hline Marital status & Vaginismus/LPV n (\%) & Controls n (\%) & $\begin{array}{l}\text { P-value } \\
0.001\end{array}$ \\
\hline Married & $446(17.6 \%)$ & $80745(18.9 \%)$ & \\
\hline Unmarried & $2071(81.8 \%)$ & $341575(79.8 \%)$ & \\
\hline Divorced/Widowed & $16(0.6 \%)$ & $5912(1.4 \%)$ & \\
\hline Working status & & & 0.012 \\
\hline Employed & $2079(82.1 \%)$ & $359348(83.9 \%)$ & \\
\hline Unemployed & $454(17.9 \%)$ & $68884(16.1 \%)$ & \\
\hline BMI kg/m² & & & $<0.001$ \\
\hline$<18.49$ & $30(3.3 \%)$ & $4486(2.2 \%)$ & \\
\hline $18.5-24.99$ & $678(74.5 \%)$ & $129601(64.8 \%)$ & \\
\hline $25.0-29.99$ & $162(17.8 \%)$ & $45473(22.7 \%)$ & \\
\hline $30.0-34.99$ & $31(3.4 \%)$ & $14194(7.1 \%)$ & \\
\hline$>35$ & $9(1.0 \%)$ & $6386(3.2 \%)$ & \\
\hline Educational level & & & $<0.001$ \\
\hline Elementary & $77(3.0 \%)$ & $26613(6.2 \%)$ & \\
\hline High school & $793(31.3 \%)$ & $174611(41.0 \%)$ & \\
\hline University & $1661(65.6 \%)$ & $224649(52.8 \%)$ & \\
\hline Age at childbirth & & & 0.040 \\
\hline $17-23$ & $85(8.4 \%)$ & $22168(9.9 \%)$ & \\
\hline $24-29$ & $632(62.5 \%)$ & $131812(58.6 \%)$ & \\
\hline $30-36$ & $295(29.2 \%)$ & $70783(31.5 \%)$ & \\
\hline Nicotine use & & & 0.008 \\
\hline Yes & $418(17.8 \%)$ & $65028(15.8 \%)$ & \\
\hline No & $1935(82.2 \%)$ & $347455(84.2 \%)$ & \\
\hline Parents country of birth & & & 0.583 \\
\hline $\begin{array}{l}\text { Both parents born in } \\
\text { Scandinavia }\end{array}$ & $2445(96.2 \%)$ & $424462(96.0 \%)$ & \\
\hline $\begin{array}{l}\text { One or both parents born } \\
\text { outside of Scandinavia }\end{array}$ & $97(3.8 \%)$ & $17827(4.0 \%)$ & \\
\hline
\end{tabular}


Table 2 Mode of delivery and parity among the study groups

\begin{tabular}{llll}
\hline & Vaginismus/LPV n (\%) & Controls n (\%) & P-value \\
Mode of delivery & & & $<0.001$ \\
Vaginal & $654(64.6 \%)$ & $160252(71.3 \%)$ & \\
Instrumental & $138(13.6 \%)$ & $26270(11.7 \%)$ & \\
Emergency caesarean section & $95(9.4 \%)$ & $19622(8.7 \%)$ & \\
Elective caesarean section & $83(8.2 \%)$ & $14802(6.6 \%)$ & \\
$\begin{array}{l}\text { Caesarean section on maternal } \\
\text { request }\end{array}$ & $40(4.0 \%)$ & $3387(1.5 \%)$ & \\
Missing & $2(0.2 \%)$ & $433(0.2 \%)$ & \\
Parity & & & \\
Nulliparous & $1542(60.4 \%)$ & $220866(49.6 \%)$ & \\
Parous & $1012(39.6 \%)$ & $224766(50.4 \%)$ & \\
\hline
\end{tabular}


Table 3 Odds ratio (OR) and adjusted odds ratio (adj.OR*) for mode of delivery in women with vaginismus/LPV

\begin{tabular}{lllll}
\hline Mode of delivery & OR & $\mathbf{9 5 \%}$ CI & Adj. OR* & 95\% CI \\
$\begin{array}{l}\text { Instrumental delivery } \\
\text { Emergency caesarean }\end{array}$ & $1.28^{* *}$ & $1.07-1.55$ & 1.16 & $0.95-1.41$ \\
$\begin{array}{l}\text { section } \\
\text { Elective caesarean }\end{array}$ & $1.37^{* *}$ & $0.96-1.47$ & $1.38^{* *}$ & $1.10-1.75$ \\
$\begin{array}{l}\text { section } \\
\begin{array}{l}\text { Caesarean section on } \\
\text { maternal request }\end{array}\end{array}$ & $2.89^{* *}$ & $1.09-1.72$ & $1.42^{* *}$ & $1.10-1.84$ \\
\hline
\end{tabular}

* Adjusted for age, nicotine use, BMI, marital status, working status, educational level and perineal laceration.

$* * \mathrm{p}<0.05$ 